\title{
Research on Mechanisms of Electric Conduction in the $p$-Type Silicon Implanted with $\mathrm{Ne}^{+}$Ions
}

\author{
P. WEGIEREK* AND P. BILlEWICZ \\ Lublin University of Technology, Nadbystrzycka 38A, 20-618 Lublin, Poland
}

\begin{abstract}
The article presents the results of research on alternating-current electric conduction in boron-doped silicon $(\rho=10 \Omega \mathrm{cm})$, strongly defected by the implantation of $\mathrm{Ne}^{+}$ions $\left(D=1.5 \times 10^{14} \mathrm{~cm}^{-2}, E=100 \mathrm{keV}\right)$. The analysis of changes in electrical characteristics recorded at the sample annealing temperature of $T_{\mathrm{a}}=373 \mathrm{~K}$ has been presented, concerning the influence of the testing temperature ranging from $253 \mathrm{~K}$ to $368 \mathrm{~K}$ as well as the frequency from $50 \mathrm{~Hz}$ to $5 \mathrm{MHz}$. The obtained results have confirmed the occurrence of two electric conduction mechanisms in strongly defected semiconductors, such as the band conduction mechanism that is characteristic of low frequency values and the jump conduction one that corresponds to higher frequencies.
\end{abstract}

DOI: 10.12693/APhysPolA.123.948

PACS: 61.72.uj, 61.72.Cc, 72.80.Ey

\section{Introduction}

The research has been carried out on boron-doped silicon of $\rho=10 \Omega \mathrm{cm}$ resistivity, implanted with $\mathrm{Ne}^{+}$ ions of the $E=100 \mathrm{keV}$ energy and a fluence of $D=$ $1.5 \times 10^{14} \mathrm{~cm}^{-2}$ using the implanter with the ion source described in [1-5]. The samples have been isochronously annealed for the time of $15 \mathrm{~min}$, within the $T_{\mathrm{a}}$ temperature range from $323 \mathrm{~K}$ to $873 \mathrm{~K}$, with an average increase rate of $(30 \div 50) \mathrm{K}$. The values of measured electrical parameters $\left(C_{p}, \sigma\right)$ have been recorded within the $T_{\mathrm{p}}$ temperature range from the liquid nitrogen temperature (LNT) to $373 \mathrm{~K}$ and at the frequencies ranging from $50 \mathrm{~Hz}$ to $5 \mathrm{MHz}$. In order to determine the influence of impurity concentration on the measured parameters, the results of research carried out on the samples of $\rho=0.07 \Omega \mathrm{cm}$ and $\rho=0.01 \Omega \mathrm{cm}$ resistivity have been included in the article as well. The experimental frequency dependences, obtained for the annealing temperature of $T_{\mathrm{a}}=373 \mathrm{~K}$ have been under discussion. Implantation conditions and annealing temperature have been determined on the basis of earlier works [6,7]. An analysis of temperature dependences of capacity and conductivity has made it possible to estimate the values of conduction activation energy $\Delta E$ and defects relaxation time. This allowed to identify types of particular defects of the tested structure [8] and, above all, to determine electric conduction mechanisms, which have occurred in the silicon layers strongly defected by ion implantation.

\section{Analysis of the obtained results}

In the first stage of experimental results evaluation, the frequency dependences of conductivity have been analysed for the samples of different boron impurities concentration (Fig. 1). Considering the relative position of

*corresponding author; e-mail: p.wegierek@pollub.pl the $\sigma=\mathrm{f}(f)$ curves, plotted for the silicon layers defected by neon ions implantation, it is possible to observe that the presented plots are nearly the same, despite the fact that values of resistivity of particular samples differ from each other by three orders of magnitude. Such tendency could be explained by appearance of the jump mechanism of electric charge transfer between particular defects. As it is known, the total conductivity can be expressed as a superposition of the two components, band one and the jump one [9]. The analysis of the dependences shown in Fig. 1 leads to the conclusion that in the described case the total conductivity is strongly dominated by the jump component. Otherwise, the sample conductivity should be inversely proportional to its resistivity, which would cause relative curves displacement.

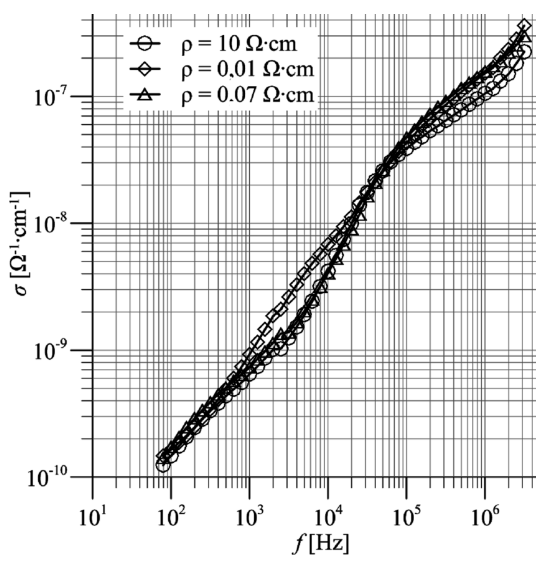

Fig. 1. Dependences $\sigma=\mathrm{f}(f)$ for samples of boron-doped silicon of different resistivities, implanted with $\mathrm{Ne}^{+}$ions with fluence $D=1.5 \times 10^{14} \mathrm{~cm}^{-2}$ and energy $E=100 \mathrm{keV}$, annealed at $T_{\mathrm{a}}=373 \mathrm{~K}$, measured at $T_{\mathrm{p}}=298 \mathrm{~K}$.

The second stage of the analysis of electric conduction mechanisms in the strongly defected $p$-type silicon included determination of the extent of influence of testing 
frequency (Figs. 2, 3) and annealing temperature (Fig. 4) on conductivity and capacity of the tested sample.

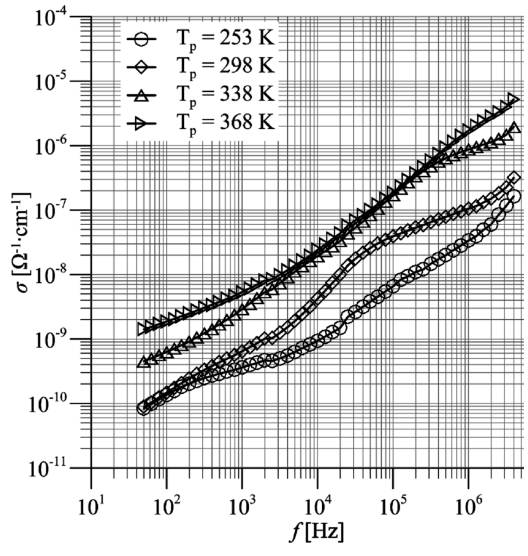

Fig. 2. Dependences $\sigma=\mathrm{f}(f)$ for sample of $p$-type silicon of $\rho=10 \Omega \mathrm{cm}$, implanted with $\mathrm{Ne}^{+}$ions with fluence $D=1.5 \times 10^{14} \mathrm{~cm}^{-2}$ and energy $E=100 \mathrm{keV}$, annealed at $T_{\mathrm{a}}=373 \mathrm{~K}$.

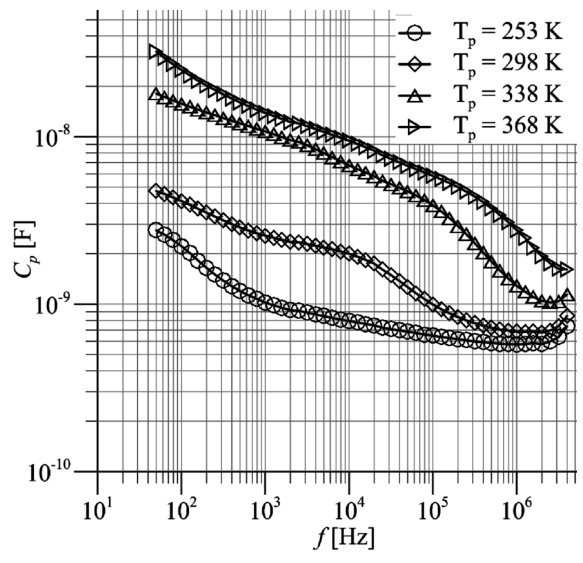

Fig. 3. Dependences $C_{p}=\mathrm{f}(f)$ for sample of $p$-type silicon of $\rho=10 \Omega \mathrm{cm}$, implanted with $\mathrm{Ne}^{+}$ions with fluence $D=1.5 \times 10^{14} \mathrm{~cm}^{-2}$ and energy $E=100 \mathrm{keV}$, annealed at $T_{\mathrm{a}}=373 \mathrm{~K}$.

In Figs. 2 and 3 it can be seen that an increase in the testing temperature $T_{\mathrm{p}}$ causes rise of the $\sigma$ and $C_{p}$ values. What is more, for the temperatures higher than $253 \mathrm{~K}$ two stages of additional polarization were distinguished, one which corresponds to low frequencies and the other one that is characteristic of high frequencies. They are related to two types of radiation defects that affect the values of measured properties.

By analyzing the dependences of conductivity on the annealing temperature $\sigma=\mathrm{f}\left(T_{\mathrm{a}}\right)$, presented in Fig. 4, it was possible to distinguish temperature ranges that correspond to certain processes. At $T_{\mathrm{a}}<423 \mathrm{~K}$ only insignificant conductivity swings were observed, which means that the charge carrier compensation rate in the allowed energy band is constant and results from a rele-

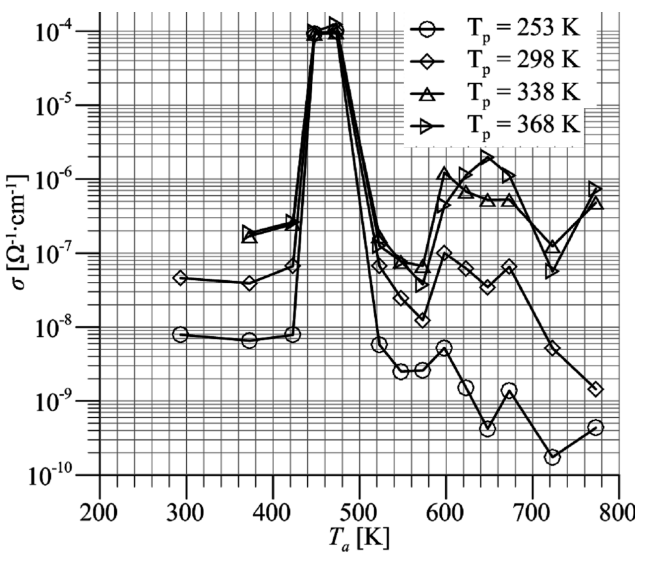

Fig. 4. Dependences $\sigma=\mathrm{f}\left(T_{\mathrm{a}}\right)$ for sample of $p$-type silicon of $\rho=10 \Omega \mathrm{cm}$, implanted with $\mathrm{Ne}^{+}$ions with fluence $D=1.5 \times 10^{14} \mathrm{~cm}^{-2}$ and energy $E=100 \mathrm{keV}$, measured at $f=100 \mathrm{kHz}$, for different testing temperatures $T_{\mathrm{p}}$.

vant value of radiation defect concentration. For the testing temperatures ranging from $423 \mathrm{~K}$ to $473 \mathrm{~K}$ conductivity increases rapidly by four orders of magnitude and then decreases again to the previous level $\left(T_{\mathrm{a}}=483 \div 523 \mathrm{~K}\right)$. The initial phase of the described process is due to annealing of some of the radiation defects, e.g. Si-P3 and Si-P6. The second phase of this phenomenon results from the increased value of resultant concentration of deep radiation defects (e.g. Si-B3), that are so-called trapping centres for charge carriers [8]. Consequently, electron quantity decreases simultaneously causing reduction in the conductivity. For the temperatures above $580 \mathrm{~K}$ the value of $\sigma$ increases again and then insignificantly decreases. This can be caused by annealing of radiation defects which occurred at lower temperatures and also by the decrease in the concentration of such types of radiation defects as Si-P1 and Si-B3 that gradually decay as the annealing temperature rises [8].

The dependences of $\sigma$ and $C_{p}$ on the temperature for various frequency values are presented in Fig. 5. They make a basis for estimating the value of the conduction activation energy $\Delta E$, which can be used for the identification of radiation defects and the evaluation of their energies. For that reason, it was necessary to perform a fit of certain parts of characteristics $\sigma_{p}=f\left(1000 / T_{\mathrm{p}}\right)$ and $C_{p}=f\left(1000 / T_{\mathrm{p}}\right)$ with the function $\ln (y)=A x+B$. Then, the values of $\Delta E$ were calculated according to the formula

$$
\Delta E=A 1000 k(1)
$$

where $k$ is the Boltzmann constant.

The calculated values of the activation energy are given in Table.

As can be seen in Fig. 5, an increase in the value of conductivity is followed by the capacity rise. It means that the charge transfer runs by the jump conduction between the radiation defects that originally are in the 


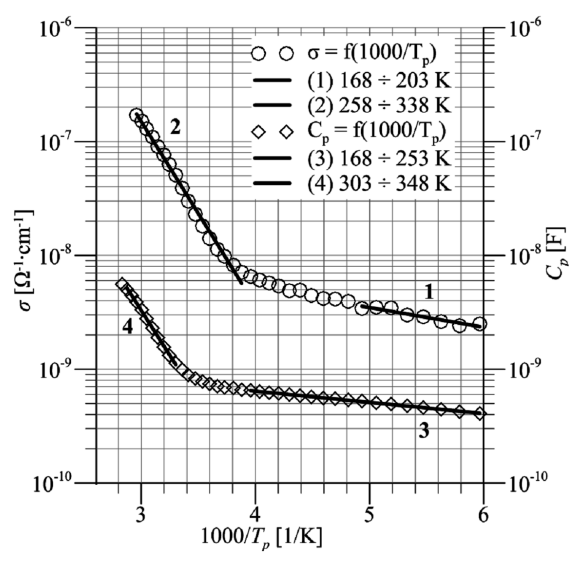

Fig. 5. Dependences of conductivity $\sigma$ and capacity $C_{p}$ on inverted temperature $1000 / T_{\mathrm{p}}$ for sample of $p$-type silicon of $\rho=10 \Omega \mathrm{cm}$, implanted with $\mathrm{Ne}^{+}$ions with fluence $D=1.5 \times 10^{14} \mathrm{~cm}^{-2}$ and energy $E=100 \mathrm{keV}$, measured at $f=100 \mathrm{kHz}$.

TABLE

Activation energy values for the testing frequency

$f=100 \mathrm{kHz}$.

\begin{tabular}{c|c|c|c}
\hline \hline $\begin{array}{c}\text { Measured } \\
\text { parameter }\end{array}$ & $\begin{array}{c}\text { Function } \\
\text { equation }\end{array}$ & $\begin{array}{c}\text { Approximation } \\
\text { range }\end{array}$ & $\begin{array}{c}\text { Activation } \\
\text { energy [eV] }\end{array}$ \\
\hline \multirow{2}{*}{$\sigma$} & $\ln (y)=-0.40 \mathrm{X}-17.48$ & 1 & 0.03 \\
& $\ln (y)=-3.72 \mathrm{X}-4.55$ & 2 & 0.32 \\
\hline \multirow{2}{*}{$C_{p}$} & $\ln (y)=-0.23 \mathrm{X}-20.26$ & 3 & 0.02 \\
& $\ln (y)=-3.68 \mathrm{X}-8.50$ & 4 & 0.32
\end{tabular}

neutral charge state. As a result of jump recharging a dipole is formed, which causes an increase of dielectric permeability and capacity of the tested sample. On the other hand, electron transfer between the radiation defects brings about conductivity increase.

High values of activation energy $(\Delta E=0.32 \mathrm{eV})$, calculated on the basis of capacity and conductivity (Table) mean that jump conduction runs over the potential barrier of the radiation defects. Those values also indicate the position of natural defect energy bands regarding the bottom of the conduction band. What should be emphasized is the fact that the values of the activation energy calculated on the basis of capacity and conductivity are equal.

According to the Mott theory [10], in the case of electrical jump conduction, the value of conductivity is the function of frequency and can be described by the following formula:

$\sigma \sim f^{\alpha}$.

With the use of analytical methods together with the characteristics presented in Fig. 2, the values of frequency coefficients $\alpha$ were calculated and are shown in Fig. 6.

As proved in [11], over the time $\tau$ from the moment of dipole formation, an electron from a negative defect can return to a positive defect, which corresponds to high-frequency conductivity, or leave a positive defect, which results in direct-current electrical conductivity. Based on the frequency $f_{\max }$, from $\alpha(f)$ characteristics shown in

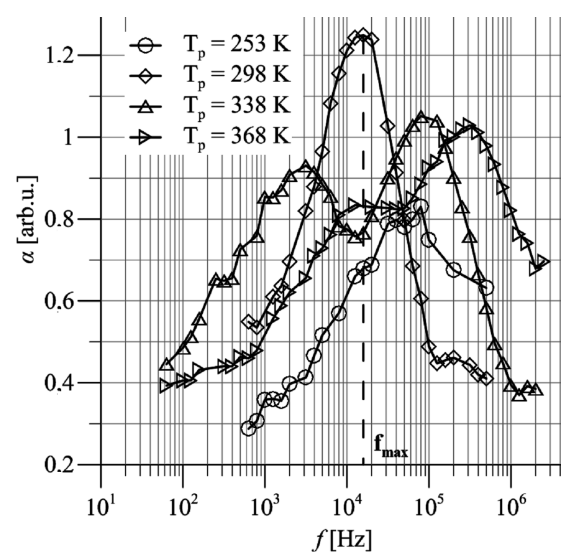

Fig. 6. Frequency coefficient $\alpha$ vs. testing frequency for the annealing temperature $T_{\mathrm{a}}=373 \mathrm{~K} ; f_{\max }$ - testing frequency value that represents a local maximum of the presented function.

Fig. 6, the time $\tau$ value can be calculated, according to the formula

$$
\tau \approx 1 / \omega=1 /(2 \pi f) .
$$

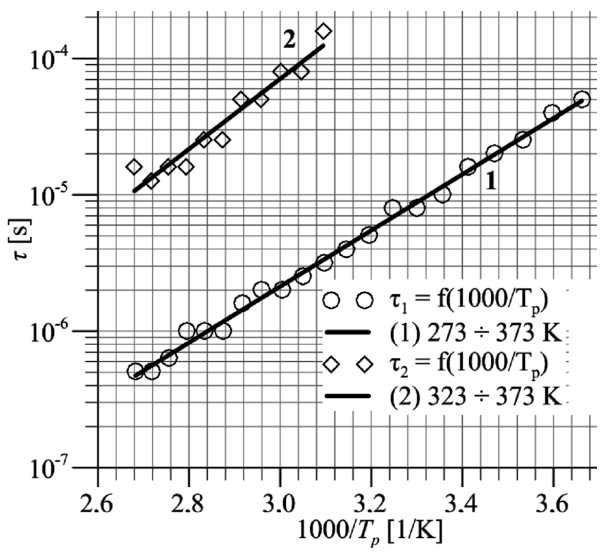

Fig. 7. Dependences of relaxation time $\tau$ on inverted temperature $1000 / T_{\mathrm{p}}$ for sample of $p$-type silicon of $\rho=$ $10 \Omega \mathrm{cm}$, implanted with $\mathrm{Ne}^{+}$ions with fluence $D=$ $1.5 \times 10^{14} \mathrm{~cm}^{-2}$ and energy $E=100 \mathrm{keV}$, annealed at $T_{\mathrm{a}}=373 \mathrm{~K}$.

In order to obtain characteristics presented in Fig. 7, the following methodology was applied. The values of frequencies $f_{\max }$ were estimated for particular testing temperatures and then it was possible to calculate the values of time while the defects responsible for particular phases of the tested sample conductivity changes stay in the charged state. The function $\tau=f\left(1000 / T_{\mathrm{p}}\right)$ was then fitted with the function $\ln (y)=A x+B$ in the same way as in the case of calculating the values of activation energies on the basis of conductivity and capacity dependences of inverted temperature $T_{\mathrm{p}}$ (Fig. 5). The values of jump conduction activation energies were subsequently estimated, according to the formula (1). The obtained 
results $\Delta E_{1}=0.41 \mathrm{eV}$ and $\Delta E_{2}=0.51 \mathrm{eV}$ correspond with the ranges of the testing temperatures; $273 \div 373 \mathrm{~K}$ and $323 \div 373 \mathrm{~K}$, respectively. The values of activation energies calculated above determine the band energy of negatively charged defects.

\section{Conclusions}

The article presents the results of research on boron-doped silicon, strongly defected by implantation of neon ions of the fluence $1.5 \times 10^{14} \mathrm{~cm}^{-2}$. These results were analyzed from the viewpoint of various mechanisms of electric conduction.

Strong dependence of electrical properties on the sample annealing temperature was observed. It was confirmed that the mentioned dependence is caused by the changes in the concentration values for various types of radiation defects. Those changes are correlated with the specific values of annealing temperature.

On the basis of dependences of capacity and conductivity on the testing frequency, it was possible to confirm appearance of two mechanisms of electric conduction, i.e. tunnelling at low frequencies and jump mechanism of electric charge transfer, appropriate for high frequency values.

It was established that two types of radiation defects are responsible for the increase of conductivity and capacity values in the testing temperature range $253 \div 368 \mathrm{~K}$. For those defects it was possible to determine the band energies for the neutral and negative charge states.

For the testing temperatures from the considered range, the values of relaxation time (which means the time while the electric charge stays in the neutral potential well after making a jump) could be published.

The experimental results obtained during the research and the conclusions formulated to summarize them are in accordance with those presented in the work [12], concerning electric conduction mechanisms in the $n$-type silicon.

\section{References}

[1] M. Turek, S. Prucnal, A. Droździel, K. Pyszniak, Rev. Sci. Instrum. 80, 043304 (2009).

[2] M. Turek, S. Prucnal, A. Drozdziel, K. Pyszniak, Nucl. Instrum. Methods Phys. Res. B 269, 700 (2011).

[3] M. Turek, A. Droździel, K. Pyszniak, S. Prucnal, J. Zuk, Przeglad Elektrotechniczny 86, 193 (2010) (in Polish).

[4] M. Turek, A. Droździel, K. Pyszniak, D. Maçzka, Przeglad Elektrotechniczny 88, 328 (2012) (in Polish).

[5] M. Turek, A. Droździel, K. Pyszniak, S. Prucnal, D. Maczka, Yu. Yushkevich, A. Vaganov, Instrum. Exp. Tech. 55, 469 (2012).

[6] P. Żukowski, J. Partyka, P. Węgierek, Phys. Status Solidi A 159, 509 (1997).

[7] J. Partyka, P. Żukowski, P. Węgierek, A. Rodzik, Y. Sidorenko, Y. Szostak, Semiconductors 36, 1326 (2002).

[8] R.C. Newman, D.N.J. Totterdell, J. Phys. C, Solid State Phys. 8, 3944 (1975).

[9] P. Węgierek, M. Kowalski, Elektronika 9, 100 (2009) (in Polish).

[10] N.F. Mott, E.A. Davis, Electronic Process in Noncrystalline Materials, Clarendon Press, Oxford 1979.

[11] P. Żukowski, T. Kołtunowicz, J. Partyka, P. Węgierek, M. Kolasik, A.V. Larkin, J.A. Fedotova, A.K. Fedotov, F.F. Komarov, L. Vlasukova, Przeglad Elektrotechniczny 3, 247 (2008) (in Polish).

[12] P. Wegierek, P. Billewicz, Acta Phys. Pol. A $\mathbf{1 2 0}$, 122 (2011). 